\title{
The Use of Endo-GIA Vascular Staplers in Liver Surgery and Their Potential Benefit: A Review
}

\author{
Peter Schemmer Helmut Friess Christos Dervenis Jan Schmidt Jürgen Weitz \\ Waldemar Uhl Markus W. Büchler \\ Department of General Surgery, Ruprecht Karls University, Heidelberg, Germany
}

\section{Key Words}

Liver resection - Stapler hepatectomy, technique - Stapler •

Parenchymal transection

\begin{abstract}
Stapling devices have been introduced for safety and to reduce the overall operative time in many surgical procedures. In hepatobiliary surgery, i.e. liver resection, several types of staplers are in use. While transection of hepatic vessels with vascular staplers is well established, their use in dissecting hepatic parenchyma has only been assessed recently. Its advantages were especially a low rate of biliary complications (i.e., bile fistulas, bilioma) and reduced bleeding. As expected, the operative time was decreased dramatically while both the complication rate in general and the overall costs for stapler hepatectomy were comparable with other techniques used in high-volume centers. Thus, endo-GIA vascular staplers can be safely used to dissect the hepatic parenchyma in a routine clinical setting with low incidence of surgical complications.

Copyright $\odot 2007$ S. Karger AG, Base
\end{abstract}

\section{Introduction}

Early milestones in the history of hepatobiliary surgery include the first successful elective liver resection, which was performed in 1888 [1], and a report of a true anatomical right hepatectomy for cancer in 1952 [2]. However, the subsequent experience with hepatic resections was far from encouraging and it was not until the last 20 years that hepatic resections have been routinely performed.

Since surgical technique is a major factor to prevent complications, various methods and instruments have been developed for safe tissue-preserving dissection of the liver parenchyma. The blunt dissection has been widely replaced by various time-consuming methods, such as the Cavitron Ultrasonic Surgical Aspirator ${ }^{\circledR}$ (CUSA) technique and the jet cutter for major liver resections. These methods represent selective dissection techniques, whereas non-selective methods include the scalpel, scissors, high-frequency coagulation and the laser technique $[3,4]$. The introduction of these surgical instruments has permitted large, non-anatomical wedge resections and liver resections to be performed with improved operative morbidity and mortality rates typically being less than 30 and 5\%, respectively, in high-volume centers [5-11]. Despite tremendous improvements in both surgical technique and perioperative patient management (especially for hemorrhage, bile leakage, hematoma, infections and postoperative liver function, all associated with high morbidity and mortality), there are still major concerns after liver resection which require a high level of training leaving it still a demanding surgical procedure. Today, staplers have become a vital instrument in the practice of many surgical specialties. Rectal,

\section{KARGER}

Fax +41613061234 E-Mail karger@karger.ch www.karger.com (c) 2007 S. Karger AG, Basel

0253-4886/07/0244-0300\$23.50/0

Accessible online at:

www.karger.com/dsu
Markus W. Büchler, MD

Department of General Surgery, Ruprecht Karls University

Im Neuenheimer Feld 110, DE-69120 Heidelberg (Germany)

Tel. +49622156 6200, Fax +496221565450

E-Mail Markus_Buechler@med.uni-heidelberg.de 


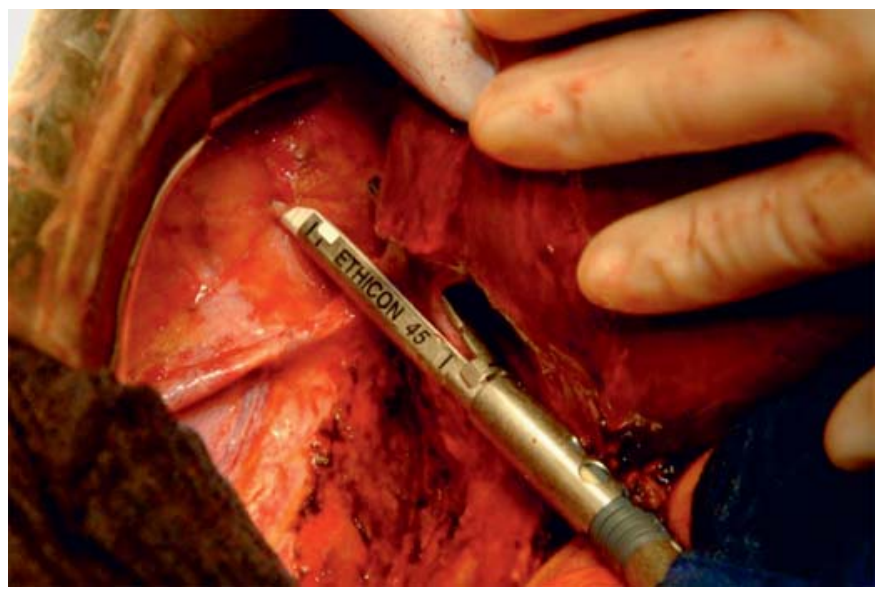

Fig. 1. Division of the right hepatic vein. The liver is mobilized and freed from its ligaments. The right liver lobe is moved to the left upper quadrant of the abdomen. Subsequently, the right hepatic vein is encircled with a white rubber band and exposed for division with an endo-GIA vascular stapler. The right hepatic vein is located between both branches of the stapler to be divided. A typical situation during closure of the right hepatic vein for right hemihepatectomy is depicted.

colonic, and esophageal anastomotic instruments allow safe and rapid anastomosis of the gastrointestinal tract, even when surgical exposure is compromised. Vascular staplers have increased the speed and safety of lobar resections of the lung $[12,13]$. Recent publications observing a number of techniques using stapling devices in liver surgery showed it to be extraordinarily helpful in the safe ligation of inflow and outflow vessels [3, 4, 14-19].

Using staplers in unroofing hepatic cysts seems to be of benefit, as any unexpectedly injured bile duct or blood vessel is so sealed [16]. With the above-mentioned motive, left lateral segmentectomies $[17,19]$ and wedge resections [20] are conducted with staplers; serving as another nonselective dissection method. Admittedly, their general routine use for transection of liver parenchyma during liver resection has not been reliably proven pertinacious and most of the literature to date gives only anecdotal evidence [19-21].

\section{Surgical Technique of Stapler Hepatectomy}

The technique referred to was introduced almost 5 years ago to our Department after L.H. Blumgart, N.Y., USA had demonstrated this procedure to the senior author of this review.

Endo-GIA Vascular Staplers for

Transection of Liver Tissue
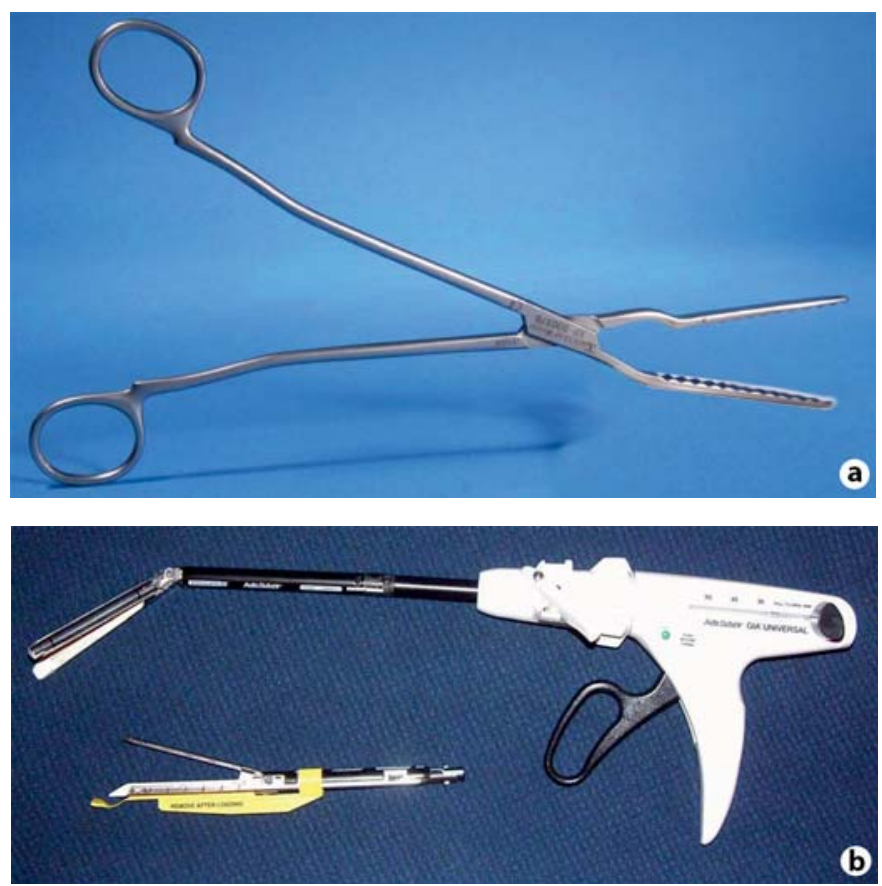

Fig. 2. Instruments for stapler hepatectomy. a Clamp developed for fraction of the hepatic parenchyma. $\mathbf{b}$ Endo-GIA vascular stapler which can be used for stapler hepatectomy.

A reversed L-shaped incision from the xiphoid to the tip of the twelfth right rib or a standard transverse abdominal incision (with or without extension in the midline to the xiphoid) is mostly made use of. Following an incipient abdominal exploration in search of extrahepatic disease, the falciform triangular ligament is then mobilized, thereafter dissection is conducted, exposing the hepatic veins and the porta hepatis. To enable the complete liver mobilization the short hepatic and caudate veins from the inferior vena cava (IVC) are clipped or ligated. In performing hemihepatectomy or extended hemihepatectomy, the adequate hepatic arterial branch is divided between ligation with sutures followed by division of the portal venous branch with the vascular stapler or via suture. Subsequently, the appropriate hepatic vein(s) are divided with the endo-GIA vascular stapler (fig. 1). The transectional line is then made afterwards and the liver capsule then divided with diathermy. To allow subsequent dissection of the hepatic parenchyma, the liver tissue was fractured stepwise with a clamp (fig. 2a, b, 3a) and subsequently divided with endo-GIA vascular staplers (fig. $2 b, 3 b$ ). Where the necessity was given, intraoperative ultrasound was used to guide the dissection. Following the resection procedure, argon beam coagula-

Dig Surg 2007;24:300-305 301 

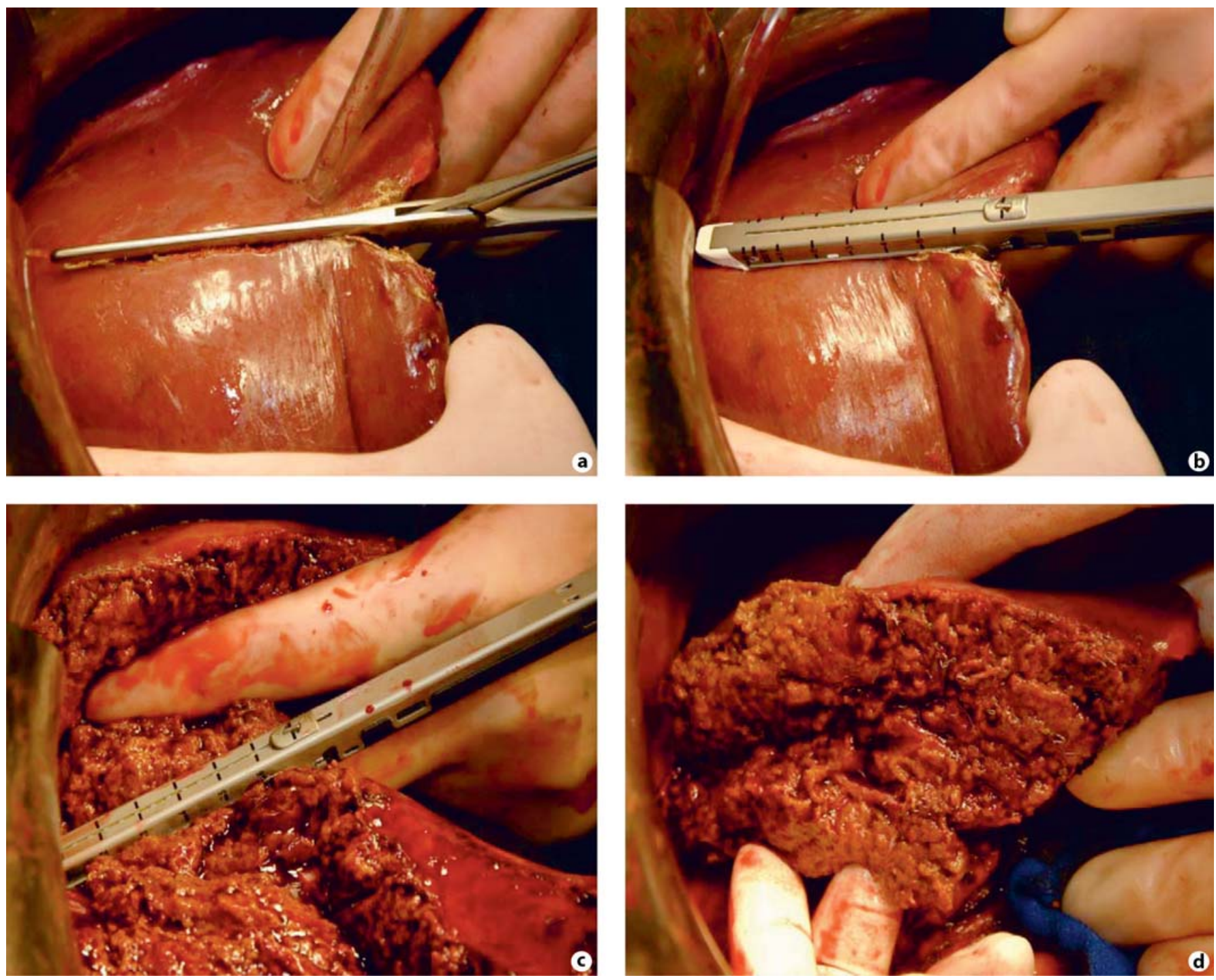

Fig. 3. Surgical steps for parenchymal transection during stapler hepatectomy. a After marking the transectional line, the liver capsule was divided with diathermy. For subsequent dissection of the hepatic parenchyma the liver tissue was fractured stepwise with a clamp as shown in figure 2a. b Crushed dissectional line with introduced stapler. c Subsequently, transection and division of the hepatic parenchyma can be performed stepwise with endo-GIA vascular staplers. d Resection (right hemihepatectomy is shown) has been completed. The dissectional plane usually does not show major oozing or leakage of bilious fluid.

tion was applied to abort minor oozing. After securing hemostasis (fig. 3d), easy-flow drains were placed in the subphrenic and subhepatic space. Using this technique of liver resection there was no need to perform Pringle's maneuver or other vascular control in $90 \%$ of all patients, as reported elsewhere [22].

\section{Discussion}

Major liver resection remains one of the more technically challenging operations. Subtle nuances in surgical technique can make a substantial difference in patient outcome. Control of operative blood loss is one of the most immediate concerns when performing liver resection. There is solid evidence of the derogatory impact of exceeding hemorrhage and blood transfusion in patients 
Fig. 4. Cost analysis in euros (EUR). For stapler hepatectomy the intraoperative costs including surgery, anesthesioloy, blood products and the average number of endo-GIA vascular staplers (Tyco 030412, $60 \mathrm{~cm}$; Tyco 030403, handset) used added up to EUR 5,197, reflecting the intraoperative costs influenced by the resection technique. The median hospital stay (EUR 4,928 ) and ICU stay (EUR 1,257) add up to a total of EUR 11,382. On average, when comparing both methods, there was a cost-benefit of more than EUR 2,400 in favor of stapler hepatectomy in this analysis.

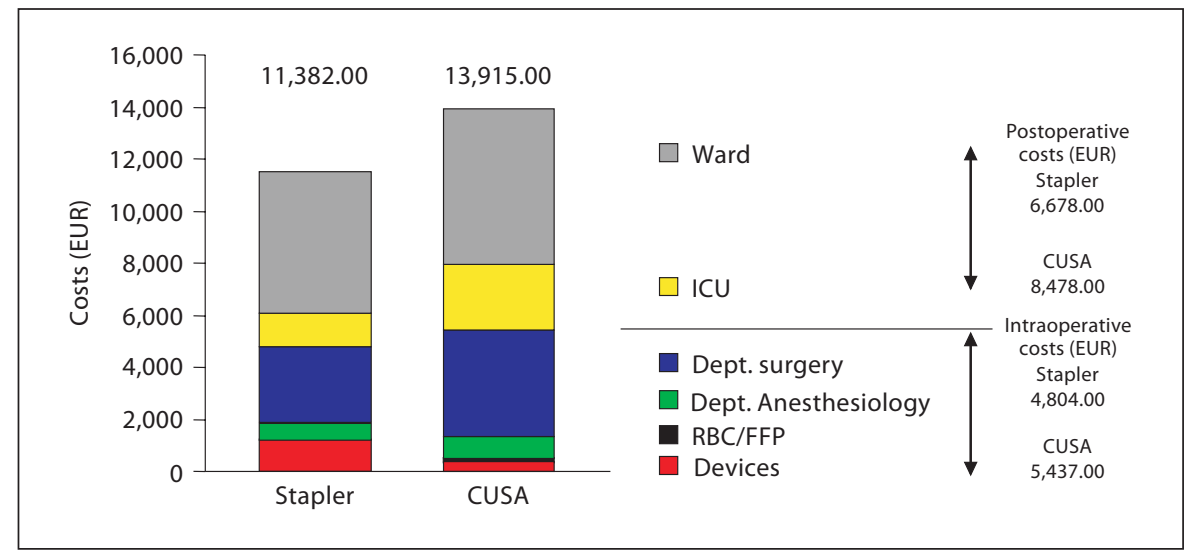

who undergo liver resection. Excessive blood loss goes along with increased perioperative morbidity and in case of colorectal metastases, a shorter disease-free interval $[23,24]$.

Since the late 1970 s, when operative mortality was $13 \%$ and more than $20 \%$ for major resections, with $20 \%$ of deaths resulting from intraoperative bleeding [25], much effort has been done to especially reduce intraoperative bleeding with both occlusion of the hepatic inflow and total vascular occlusion introduced by Bismuth et al. [26] and Huguet et al. [27] followed by others [28-30].

The employment of vascular staplers to divide hepatic veins (fig. 1) [17] and portal branches during hemihepatectomy since the 1990s is viewed as an accomplishment that has assisted in averting blood loss and hence tapering the requirement of inflow occlusion [3, 4, 14-19]. Furthermore, left lateral segmentectomies and wedge resections performed with stapler also showed favorable results $[17,19,20]$. The same results can be obtained with laparoscopy and stapler for unroofing of hepatic cysts since any inadvertently injured bile duct or blood vessel is sealed. Stapling devices can be especially useful in patients with coagulopathy and in the treatment of complex liver abscesses [14-16, 19, 31]. However, it was only most recently that a large series of staplers being used for the phase of parenchymal transection for liver resection was published. A series of 300 patients who underwent stapler hepatectomy was documented prospectively to elucidate whether this technique for parenchymal dissection is applicable in a routine clinical setting. Both its feasibility and safety with its associated surgical risk factors for the development of postoperative complications were assessed [22].

Based on the results of the described study, it was concluded that parenchymal transection with endo-GIA vascular staplers is a feasible and safe technique for liver resection with mortality (4\%) and morbidity (33\%) as low as in recently published large series of non-selected patients who underwent liver resection in other high-volume centers [5, 32-34]. In contrast to other series [5, 32, 33 , only $10 \%$ of patients underwent the Pringle maneuver and no other vascular control was applied during resection. This is indeed astonishing since a median blood loss of only $700 \mathrm{ml}$ (major resection: $800 \mathrm{ml}$, minor resection: $500 \mathrm{ml}$ ) during stapler hepatectomy was recorded. In antagonisim to this, Jarnagin et al. reported of a moderate blood loss of $600 \mathrm{ml}$; nevertheless, $\geq 3$ segments resection which confers to major hepatectomy in their investigations led to a blood loss of more than $1,000 \mathrm{ml}$, which in turn contrasts to $800 \mathrm{ml}$ observed in the cases of stapler hepatectomy [5, 22]. Moreover, a median blood loss between 1,000 and $1,325 \mathrm{ml}$ is reported in a series including $\geq 70 \%$ cases of hepatic vascular exclusion-aided major hepatectomy [35]. Analogous values were published for blood loss during liver resection with portal triad clamping or extrahepatic control of the hepatic veins $[28,34]$. This led to the transfusion of blood products in up to $50 \%$ of the cases $[28,34]$. More recently, 750 $\mathrm{ml}$ was reported as the median intraoperative blood loss and about $17 \%$ of patients in this study report required transfusion. However, 27\% of their patients underwent the Pringle maneuver during liver resection which is in contrast to stapler hepatectomy [22,33]. With inflow and outflow control before dissection of liver parenchyma, a more substantial reduction of the intraoperative blood loss can be attained. The fact that hepatic vascular exclusion associates with unpredictable hemodynamic intolerance, increased postoperative complications which results in longer hospital stay its application should be restricted to lesions involving the cavo-hepatic intersection 
[28]. Moreover, the extended Pringle maneuver may lead to complications due to ischemic injury of the remnant liver and abdominal visceral venous stagnation [36]. Following stapler hepatectomy there was no need for RBCs and FFPs transfusion in 84 and $89 \%$ of cases. For patients requiring transfusion, a median of 3 units RBC and 4 units FFP were endowed [22].

One of the major obstacles after liver resection is biliary leakage and bilioma with a persistently high incidence. After stapler hepatectomy, bile leak or bilioma was recorded in only $8 \%$ of cases [22] which can rarely be achieved with conventional resection techniques [37]. The innovative advantage of using staplers is that they are generally very fast, in contrast to CUSA. If this is confirmed in a randomized prospective clinical trial, this would present significant advantages for both the patient and the surgeon.

Treatment costs become more and more a focus in clinical medicine, thus novel methods need to be evaluated not only for patient's safety but also for their cost-effectiveness. For stapler hepatectomy the most recently performed evaluation of the intraoperative costs (including surgery, anesthesioloy, blood products and the average number of endo-GIA vascular staplers (Tyco 030412,
$60 \mathrm{~cm}$; Tyco 030403, handset)), the median hospital stay and ICU stay added up to a total of EUR 11,382. Most interestingly, there was a cost-benefit when comparing stapler and conventional methods of more than EUR 2,400 in favor of stapler hepatectomy (fig. 4) [22].

\section{Clinical Implications}

Employing endo-GIA vascular staplers for transection of liver tissue is auspicious; taking into account the data recently published [22], stapler hepatectomy may prove to be an expedient, broadly applied and safe method for the parenchymal phase of liver resection with a morbidity and mortality which may match up to that of conventional resection techniques utilized by other high-volume centers [5-11]. Stapler hepatectomy, being both an efficient and reliable surgical procedure, calls for the necessity of controlled clinical trials so as to further investigate and improve this liver resection technique.

\section{Acknowledgement}

We thank Genevieve Dei-Anane for language editing of the manuscript.

\section{References}

1 Langenbuch C: Ein Fall von Resektion eines linksseitigen Schnurlappens der Leber: Heilung. Berl Klin Wochenschr 1888;25:37-38.

2 Lortat-Jacob J, Robert H: Hépatectomie droite réglée. Presse Méd 1952;60:549-551.

3 Blumgart LH, Fong Y (eds): Surgery of the Liver and the Biliary Tract, ed 3. London, Saunders, 2000.

4 DeMatteo RP, Fong Y, Jarnagin WR, Blumgart LH: Recent advances in hepatic resection. Seminars in Surgical Oncology 2000;19:200-207.

-5 Jarnagin WR, Gonen M, Fong Y, DeMatteo RP, Ben-Porat L, Little S, Corvera C, Weber S, Blumgart LH: Improvement in perioperative outcome after hepatic resection. Analysis of 1803 consecutive cases over the past decade. Ann Surg 2002;236:397-407.

-6 Scheele J, Stangl R, Altendorf-Hofmann A, et al: Resection of colorectal liver metastases. World J Surg 1995; 19:59-71.

-7 Nordlinger B, Guiguet M, Vaillant JC, et al: Surgical resection of colorectal carcinoma metastases to the liver. A prognostic scoring system to improve case selection, based on 1,568 patients. Cancer 1996;77:1254-1262.
8 Gayowski T, Iwatsuki S, Madariaga JR, Selby R, Todo S, Irish W, Starzl TE, Hafner GH: Experience in hepatic resection for metastatic colorectal cancer: analysis of clinical and pathological risk factors. Surgery 1994;116: 703-710.

9 Fong Y, Fortner J, Sun RL, Brennan MF Blumgart LH: Clinical score for predicting recurrence after hepatic resection for metastatic colorectal cancer: analysis of 1,001 consecutive cases. Ann Surg 1999;230:309318.

10 Fan ST, Lo CM, Liu CL, et al: Hepatectomy for hepatocellular carcinoma: toward zero hospital deaths. Ann Surg 1999;229:322330.

-11 Redaelli CA, Dufour J-F, Wagner M, Schilling $M$, Hüsler J, Krähenbühl L, Büchler MW, Reichen J: Preoperative galactose elimination capacity predicts complications and survival after hepatic resection. Ann Surg 2002;235:77-85.

12 Lewis RJ: The role of video-assisted thoracic surgery for carcinoma of the lung: wedge resection to lobectomy by simultaneous individual stapling. Ann Thorac Surg 1993;56: 762-768.
13 Sugarbaker DJ, Metzner SJ: Improved technique for hilar vascular stapling. Ann Thorac Surg 1992;53:165-166.

14 McEntee GP, Nagorney DM: Use of vascular staplers in major hepatic resections. Br J Surg 1991;78:40-41.

15 Voyles CR, Vogel S: Hepatic resection using stapling devices to control the hepatic veins. Am J Surg 1989;158:459-460.

16 Fong Y, Blumgart LH: Useful stapling techniques in liver surgery. J Am Coll Surg 1997; 185:93-100.

17 Trede M: Einsatz eines laparoskopischen Einweg-Klammernahtinstruments bei Leberresektion. Chirurg 1993;64:406-407.

18 Wrightson WR, Edwards MJ, McMasters EM: The role of the ultrasonically activated shears and vascular cutting stapler in hepatic resection. Am Surg 2000;66:1037-1040.

19 Jurim O, Colonna II JO, Colquhoun SD, Shaked A, Busuttil RW: A stapling technique for hepatic resection. J Am Coll Surg 1994; 178:510-511.

20 Lefor AT, Flowers JL: Laparoscopic wedge biopsy of the liver. J Am Coll Surg 1994;178: 307-308. 
21 Zilling T, Walther BS, Holmin T: Segmental liver resection with linear stapling device. An experimental study on pigs. In Vivo 1990; 4:273-275.

-22 Schemmer P, Friess H, Hinz U, Mehrabi A, Kraus TW, Z'graggen K, Schmidt J, Uhl W, Büchler MW: Stapler hepatectomy is a safe dissection technique: analysis of 300 patients. World J Surg 2006;30:419-430.

-23 Yamamoto J, Kosuge T, Takayama T, et al: Perioperative blood transfusion promotes recurrence of hepatocellular carcinoma after hepatectomy. Surgery 1994;115:303-309.

-24 Rosen CB, Nagorney DM, Taswell HF, Helgeson SL, Iistrup DM, van Heerden JA, Adson MA: Perioperative blood transfusion and determinants of survival after liver resection for metastatic colorectal carcinoma. Ann Surg 1992;216:493-505.

25 Foster JH, Berman MM: Solid liver tumors. Major Probl Clin Surg 1977;22:341-342.

-26 Bismuth H, Castaing D, Garden OJ: Major hepatic resection under total vascular exclusion. Ann Surg 1989;210:13-19.

$>27$ Huguet C, Gavelli A, Addario-Chieco P, Bona S, Harb J, Joseph JM: Liver ischemia for hepatic resection: Where is the limit? Surgery 1992;111:251-259.
28 Belghiti J, Noun R, Zante E, Ballet T, Sauvanet A: Portal triad clamping or hepatic vascular exclusion for major liver resection. Ann Surg 1996;224:155-161.

29 Evans PM, Vogt DP, Mayes III JT, Henderson JM, Walsh RM: Liver resection using total vascular exclusion. Surgery 1998;124:807815.

30 Buell JF, Koffron A, Yoshida A, Hanway M, Lo A, Layman R, Cronin DC, Posner MC, Millis JM: Is any method of vascular control superior in hepatic resection of metastatic cancers? Arch Surg 2001;136:569-575.

31 Rau HG, Schauer R, Pickelmann S, Beyer BCM, Angele MK, Zimmermann A, Meimarakis G, Heizmann O, Schildberg FW: Dissektionstechniken in der Leberchirurgie. Chirurg 2001;72:105-112.

-32 Belghiti J, Hiramatsu K, Benoist S, Massault P, Sauvanet A, Farges O: Seven hundred forty-seven hepatectomies in the 1990s: an update to evaluate the actual risk of liver resection. J Am Coll Surg 2000;191:38-46.

-33 Poon RT, Fan ST, Lo CM, Liu CL, Lam CM, Yuen WK, Yeung C, Wong J: Improving perioperative outcome expands the role of hepatectomy in management of benign and malignant hepatobiliary diseases: analysis of 1,222 consecutive patients from a prospective database. Ann Surg 2004;240:698-710.
34 Cunningham JD, Fong Y, Shriver C, Melendez JA, Marx WL, Blumgart LH: One hundred consecutive hepatic resections. Blood loss, transfusion, and operative technique. Arch Surg 1994;129:1050-1056.

35 Melendez JA, Arslan V, Fisher ME, Wuest D, Jarnagin WR, Fong Y, Blumgart LH: Perioperative outcomes of major hepatic resections under low central venous pressure anesthesia: blood loss, blood transfusion, and the risk of postoperative renal dysfunction. J Am Coll Surg 1998;187:620-625.

$>36$ Kim YI, Kitano S: Segment VIII resection of the cirrhotic liver under continuous Pringle maneuver with in situ cooling followed by temporary portal decompression. Am J Surg 1999; 177:244-246.

-37 Tanaka S, Hirohashi K, Tanaka H, Shuto T, Lee SH, Kubo S, Takemura S, Yamamoto T, Uenishi T, Kinoshita H: Incidence and management of bile leakage after hepatic resection for malignant hepatic tumors. J Am Coll Surg 2002;195:484-489. 